\title{
Hiroshima: a catástrofe atômica e suas testemunhas
}

\author{
CRISTIANE IZUMI NAKAGAWA ${ }^{I}$
}

\section{Bombardeio}

No piloto de um único avião carregado com bombas de gás concentra-se toda a autoridade para privar o cidadão da luz, do ar e da vida, que na paz encontra-se dividida entre milhares de chefes de escritório. $\mathrm{O}$ modesto bombardeiro, na solidão das alturas, a sós consigo e com seu Deus, carrega uma procuração de seu superior gravemente enfermo, o Estado, e nenhuma vegetação volta a crescer onde ele põe a sua assinatura [...]. (Benjamin, 2012, p.75)

A BOMBA de urânio, em seus primeiros estágios de desenvolvimento, foi batizada pelo general Groves de "Thin Man" em homenagem ao presidente Roosevelt. Porém, ao longo do processo de criação da arma, seu formato foi sendo modificado conforme as exigências que o bombardeio impunha aos cientistas. Quando pronta, apresentava um tamanho reduzido se comparada ao modelo inicial e, por isso, passou a ser chamada pelo Projeto de "Little Boy". A bomba de plutônio, por sua vez, foi chamada de Fat Man em homenagem a Churchil (Thomas; Witts, 2012).

No dia 5 de agosto de 1945, na base de Tinan, às 15 h30, ${ }^{1}$ a bomba Little Boy deixou os galpões no qual foi montada (por motivos de segurança, as partes da bomba foram enviadas separadamente de Los Alamos à base de Tinan) para ser colocada no compartimento de bombas do Enola Gay (Thomas; Witts, 2012).

À meia-noite do dia 6 de agosto, Tibbets se dirigiu pela última vez aos 26 homens que voariam na missão, antes de chamar cada um deles individualmente para lhes dirigir algumas palavras finais. Quinze minutos depois, a tripulação foi ao encontro do capelão da base, capitão Willliam Downey, que escrevera uma oração para aquele momento.

Pai Todo-Poderoso, Que ouvirá a oração daqueles que $\mathrm{O}$ amam, nós oramos ao Senhor para que estejas com aqueles que enfrentarão as Alturas de Seu céu e que carregarão a batalha aos nossos inimigos. Vigie-os e proteja-os, nós oramos ao Senhor, enquanto voam a seus destinos. Que eles, assim como nós, conheçam Sua força e poder, e armados com Seu poder possam trazer um rápido fim a essa guerra. Nós oramos ao Senhor que o fim da guerra venha logo, e que mais uma vez nós possamos conhecer a paz na Terra. Que os homens que voarão esta noite fiquem em segurança sob Seus 
cuidados, e que possam retornar em segurança para nós. Nós seguiremos em frente confiando no Senhor, sabendo que estamos sob Seus cuidados agora e sempre. Em nome de Jesus Cristo. Amem. (Thomas; Witts, 2012, p.314, tradução nossa)

A oração escrita e pronunciada por Downey passava ao esquadrão que partiria de Tinan em algumas horas a mensagem de que a missão que estavam prestes a executar era feita em nome de Deus, na busca pelo restabelecimento da paz perturbada pelo inimigo. Os membros da equipe de Tibbets pediam a bênção e a proteção de Deus para executarem com excelência o bombardeio, partindo com a arma mais destrutiva já criada pelo homem em direção a uma cidade repleta de civis inimigos.

A aniquilação do inimigo, desde os tempos mais remotos da humanidade, busca na religião justificativas para as atrocidades cometidas contra outros seres humanos que, no caso de guerras, não têm rosto ou nome e apenas duas possibilidades de nacionalidade: aliada ou inimiga. Nesse contexto surgem as testemunhas que quebram essa impessoalidade, permitindo denunciar as atrocidades cometidas.

O esquadrão que voaria para Hiroshima, arriscando suas vidas em nome dos Estados Unidos, de Deus e da paz, compartilhava a mesma crença dos japoneses que morreram e mataram durante a mesma guerra em nome de seu imperador, personificação de seu Deus e de seu país. Todos eles, abençoados por suas respectivas divindades e cumprindo ordens de seus governantes, arriscaram suas vidas por motivos diferentes dos que comandavam seus destinos e que os usaram de forma autoritária em nome de interesses políticos e econômicos. Ou seja, todos aqueles que morreram ou arriscaram suas vidas pelo país durante a guerra eram apenas os braços, os meios pelos quais seus governos buscavam alcançar seus objetivos. $\mathrm{O}$ autoritarismo imposto àqueles que cumpriam ordens com excelência se dava por meio da ideologia de que lutavam por algo divino, contra o mal e a favor da paz.

No caso do bombardeio atômico, o grau de dominação atinge um patamar no qual os indivíduos pedem a bênção de seu Deus para aniquilar milhares de pessoas de forma terrível, sem precedentes na história da humanidade. Que Deus, independentemente da religião, abençoa um genocídio? Ao mesmo tempo, muitos sobreviventes de Hiroshima afirmam que, após a explosão, ao verem a cidade incendiando, pessoas mutiladas e carbonizadas, as construções destruídas, a população desnorteada, chorando, uivando e gemendo de dor, gritos desesperados de socorro de vítimas que estavam aprisionadas embaixo de escombros e sendo engolidas pelo fogo - ou seja, em suas palavras "a imagem do inferno católico na Terra" - chegaram a se questionar, num primeiro momento, sobre a razão pela qual Deus os estava punindo daquela forma? Qual pecado haviam cometido para serem submetidos a uma prova terrível como aquela? Como afirmou um representante do Vaticano em sua visita ao Memorial da Paz de 
Hiroshima, o que aconteceu no dia 6 de agosto de 1945 não foi obra de Deus, mas exclusivamente obra do homem.

Dez minutos após a oração de Downey, em Hiroshima, o alarme de ataque aéreo soou, deixando a população de prontidão e em seus abrigos. À 1 h37min, os três aviões de reconhecimento climático partiram de Tinan e, à 1 h5 $1 \mathrm{~min}$, o avião Top Secret partiu em direção a Iwo Jima, onde permaneceria de prontidão caso houvesse algum imprevisto com os demais aviões destinados à missão (Thomas; Witts, 2012).

Sem que nada tivesse acontecido, às $2 \mathrm{~h} 10 \mathrm{~min}$ o alarme acionado em Hiroshima à $00 \mathrm{~h} 25 \mathrm{~min}$ foi desligado, permitindo que a população pudesse voltar aos seus lares e dormir (Hiroshima Peace Memorial Museum, 1999).

Às 2h20min a equipe do Enola Gay começou a embarcar. Tibbets, sem o conhecimento do restante de sua tripulação, certificou-se de que uma pequena caixa contendo doze cápsulas de cianeto em doses letais encontrava-se em um de seus bolsos internos. Caso tivessem problemas na missão e houvesse risco de acabarem como prisioneiros em solo japonês, distribuiria as cápsulas para os demais membros da equipe e lhes daria duas opções, ambas fatais: usarem a arma que levavam consigo na missão ou a cápsula de cianeto (Thomas; Witts, 2012).

Às 2h27min os motores do bombardeiro armado com a bomba atômica foram ligados e às $2 \mathrm{~h} 35 \mathrm{~min}$ o avião estava pronto para decolar. Dez minutos depois, às 2h45min, o Enola Gay decolou. Dois minutos depois, às $2 \mathrm{~h} 47 \mathrm{~min}$, o avião Great Artiste levantou voo e, finalmente, às $2 \mathrm{~h} 49 \mathrm{~min}$, foi a vez do avião N.91. Assim, às 2h50min do dia 6 de agosto de 1945, todos os aviões designados para a primeira missão atômica da história haviam deixado Tinan e estavam a caminho do Japão (Thomas; Witts, 2012).

Em Hiroshima, a população estava em meio a uma noite conturbada uma vez que o alarme de ataque aéreo fora acionado três vezes durante a madrugada, fazendo a população correr para seus abrigos. Porém, em nenhuma das três situações houve algum tipo de ataque à cidade, e o alarme silenciou pouco tempo depois de seu disparo.

Às 6h30min, no Enola Gay, a bomba Little Boy começou a ser armada. Às 7h09min o bombardeio de reconhecimento climático Straight Flush passou pelas redondezas de Hiroshima, acionando um novo alarme de ataque aéreo na cidade e levando novamente a população para seus abrigos (Hiroshima Peace Memorial Museum, 1999).

Às 7h24min, o capitão Eatherly comunicou a Tibbets que Hiroshima apresentava perfeitas condições para o bombardeio e, consequentemente, o coronel informou à sua tripulação que voariam em direção ao alvo primário. Sete minutos após o contato do piloto do Straight Flush com o Enola Gay, o alarme em Hiroshima cessou. Porém, nesse horário (7h3lmin), a população não mais se preparava para voltar a dormir, mas para começar suas obrigações diárias ( $\mathrm{Hi}^{-}$ roshima Peace Memorial Museum, 1999). 
Às 8 h05min, Van Kirk informou aos demais que estavam a 10 minutos do alvo. Em Hiroshima, Yoshi Muraki se dirigia à escola Oshimo Middle School para mulheres, caminhando ao lado da ponte Aioi e observando os alunos da sétima e oitava séries já trabalhando nas áreas de demolição. Às $8 \mathrm{~h} 12 \mathrm{~min}$, Van Kirk alertou aos tripulantes que estavam in point, ou seja, sobre o alvo. Dois minutos depois, em Saigo, distante 19 milhas a leste de Hiroshima, um observador avistou os três bombardeiros se aproximando e correu para avisar o centro de comunicações baseado no castelo de Hiroshima (instalação militar). No mesmo minuto, Tibbets alertou todos os tripulantes para que colocassem seus óculos protetores, com exceção daqueles que precisariam executar algum comando, isto é, Tibbets, Ferebee e Beser. Nesse mesmo instante, Ferebee acionou o botão que contaria 15 segundos para a liberação da bomba (Thomas; Witts, 2012).

Em sincronia, a uma milha de distância do Enola Gay, Kermit Beahan preparava-se para liberar os equipamentos científicos do Great Artiste e, a duas milhas, o N.91 executara uma curva de 90 graus para tirar uma foto da cidade antes da explosão.

Precisamente às $8 \mathrm{hl} 15 \mathrm{~min} 17 \mathrm{segs}$, as portas do compartimento de bomba do Enola Gay se abriram e, dentro do bombardeiro em Iwo Jima e em Tinan, todos escutaram ansiosos e tensos Ferebee dizer: "bomba liberada" (Thomas; Witts, 2012, p.337, tradução nossa).

Assim que as portas se fecharam, Tibbets imediatamente fez a manobra que planejara, seguido por Sweeney e pelo piloto do avião N.91. Como previram Groves e Tibbets, os três bombardeiros envolvidos no lançamento da bomba atômica entraram nos céus da cidade de Hiroshima sem serem devidamente anunciados pelos alarmes aéreos que soaram várias vezes ao longo da noite, mas falharam em alertar a população para o verdadeiro ataque. Quando foi possível avistar os B-29 a partir de Saigo, já era tarde e a bomba já havia sido liberada (Hiroshima Peace Memorial Museum, 1999).

Segundos antes de a explosão ocorrer, o aviso de Saigo chegou por rádio a Hiroshima e seu receptor correu para comunicar à população sobre os três aviões avistados. Seu comunicado, porém, fora interrompido na metade. Eram 8h16min da manhã de 6 de agosto de 1945 (Thomas; Witts, 2012).

\section{Explosão}

A bomba caiu por 43 segundos e explodiu a 600 metros de altura em relação ao solo, acima do hospital Shima, localizado a 300 metros a sudeste da ponte Aioi. A explosão no ar e não no solo, como demonstrado no teste Trinity, foi meticulosamente calculada pelos cientistas como uma forma de potencializar a explosão e os danos dela decorrentes ${ }^{3}$ (Hiroshima Peace Memorial Museum, 1999).

A explosão da bomba atômica liberou gigantescas quantidades de energia, que fizeram reluzir no céu um flash muito intenso, descrito por muitos sobreviventes como semelhante a um flash de magnésio como os utilizados pelas má- 
quinas fotográficas, mas em proporções monstruosas. A luz emitida era tão forte que pôde ser vista a quilômetros de distância do epicentro ${ }^{4}$ (Hiroshima Peace Memorial Museum, 1999).

Yoshi Muraki estava dentro do prédio de sua escola quando ouviu o barulho dos B-29 e, em seguida, foi surpreendida por um clarão amarelo muito intenso e uma explosão ensurdecedora. Foi levantada no ar e perdeu a consciência. Já Teru Furuta ${ }^{5}$ não chegou a desmaiar. Estava saindo de casa para se juntar ao seu grupo de trabalho do Students Mobilization quando viu o clarão e ouviu o barulho estremecedor. Foi jogado ao chão, onde ficou deitado protegendo seus olhos e ouvidos até ter coragem de se mexer.

Para os observadores dos B-29 que levaram a bomba até o alvo, a luz gerada pela explosão era de uma cor nunca vista pelo homem na natureza, roxa e avermelhada, muito intensa e bonita, que gerou uma gigantesca e monstruosa bola de fogo (Thomas; Witts, 2012). Essa bola de fogo, semelhante a um pequeno sol com o diâmetro de 280 metros, atingiu uma temperatura de aproximadamente 3.500 graus Celsius. A diferença de pressão gerada no epicentro fez que a bola de fogo fosse seguida de uma violenta explosão (bigh-pressure blast, a shock wave) que liberou radiação e raios de calor em todas as direções, destruindo e queimando tudo no 1,5 quilômetro ao redor do epicentro e causando destruição e incêndios parciais entre 1,5 e 4,0 quilômetros ao redor do epicentro. A destruição da cidade foi causada por energia térmica (35\%), pela pressão (50\%), e pela radiação (15\%) (Hiroshima Peace Memorial Museum, 1999).

Em dez segundos, a onda de choque atravessou 3,7 quilômetros de distância ao redor do epicentro, exercendo uma força de 19 toneladas por metro quadrado nos primeiros 500 metros de distância. O resultado dessa onda foi a rápida queda de pressão no exato local da explosão que, como reflexo, "sugou" violentamente uma grande quantidade de ar, dando origem a uma onda reversa na direção das áreas ao redor do ponto de explosão.

Yoshi Muraki retomou a consciência e demorou um pouco para assimilar onde estava. Percebeu que se encontrava embaixo da calha de uma casa, mas não da escola onde estava quando a bomba explodiu. Estava confusa. Olhou para o lado e viu um estudante inconsciente com os olhos perfurados por estilhaços de vidro. Percebeu que estava tudo escuro. Podendo se mexer, saiu debaixo dos escombros e viu que tudo ao seu redor estava destruído. Desnorteada, começou a caminhar e viu pessoas caminhando em filas, umas atrás das outras, com olhares sem vida e sem consciência, aparentemente sem saberem para onde estavam indo. Apenas caminhavam em silêncio. Quando olhou com atenção, surpreendeu-se ao perceber que todos os que caminhavam estavam nus.

Tsuda, que se encontrava na província vizinha a Hiroshima, não foi atingida diretamente pela explosão, mas sentiu a forte onda de choque proveniente da bomba. Ouviu um estrondo e, em seguida, teve todos os vidros de sua casa quebrados e as portas derrubadas. Sua família estava assustada mas bem. 
Kamatsuka estava na capela esperando a missa da manhã quando a explosão derrubou a estrutura do prédio onde estava, soterrando-a sob as ruínas. Conseguiu se desvencilhar dos entulhos e viu uma Hiroshima totalmente destruída. Reparou que não havia construções em pé e que não havia espaço para caminhar por conta dos detritos que se espalhavam por todos os lados. Encontrou-se com alguns colegas que também conseguiram se desvencilhar dos entulhos e decidiram ir em direção ao refúgio que lhes foi designado caso houvesse bombardeio. Preparados para partir, Kamatsuka ouviu gemidos abafados de socorro.

Apesar de ninguém visível, eu podia dizer que, devido à quantidade de gemidos, havia muitas pessoas presas embaixo da parede derrubada. Nós tentamos levantar a parede, mas somente com a força de algumas garotas a parede não se movia. Nós chamávamos pelos nossos colegas de sala soterrados embaixo da parede para os encorajar; não havia mais nada que pudéssemos fazer. O tempo passou em frustração. Não sabíamos mais o que fazer. Foi quando nosso diretor da escola, Sr. Takuo Matsumoto, apareceu e nos mandou fugir. "É uma bênção vocês terem sobrevivido. O fogo está se aproximando, então eu quero que vocês escapem imediatamente para o Mt. Ushita. Certo?", ele disse, quase gritando. Percebemos que havia chegado a hora de dizermos adeus para nossos amigos. Ficávamos olhando para trás, pedindo desculpas em nossos corações e juntando nossas mãos em oração. Eu ainda, até hoje, ouço meus amigos suplicando por ajuda. (Hiroshima Jogakuin Alumni Association, 2005, p.72, tradução nossa)

No mesmo local, Mitsuko Koshimizu. ${ }^{6}$ acordou coberta de sangue da amiga que, alguns minutos antes, estava conversando animadamente com ela e agora encontrava-se morta ao seu lado. Assustada e sabendo que estava soterrada, Koshimizu se desvencilhou dos escombros e conseguiu sair debaixo do prédio demolido. Começou a caminhar quando ouviu uma amiga pedindo socorro. Koshimizu conta que tentou de todas as formas remover os escombros que prendiam a amiga, mas sem sucesso. Conta que jamais se esquecerá do desespero da amiga ante a possibilidade de morrer no fogo:

"Por favor, me ajude! Corte minha perna para me salvar!" gritou minha amiga. Era um choro estridente de alguém que estava encarando a morte. $\mathrm{O}$ fogo que nos cercava estava se aproximando. Eu ainda posso ouvir a voz da minha amiga ressoando no meu ouvido. Tudo o que eu pude dizer foi, "Eu sinto muito, eu realmente sinto muito por não poder te salvar". Ela ficou em silêncio com minhas palavras. Seu silêncio me agarrou de tal forma que eu não consegui fugir. (Hiroshima Jogakuin Alumni Association, 2005, p.109, tradução nossa)

Os raios de calor emanados pela bomba atômica fizeram que Hiroshima atingisse temperaturas muito elevadas e, consequentemente, incêndios alastraram-se pela cidade queimando tudo o que havia restado da explosão. Esses incêndios tiveram seus ápices entre 10h00min e 15h00min do dia 6 de agosto, e 
continuaram pelos próximos cinco ou seis dias. Os dois quilômetros da cidade ao redor do epicentro queimaram completamente (Hiroshima Peace Memorial Museum, 1999).

Furuta encontrou os incêndios quando se livrou dos escombros e caminhou até a linha do streetcar. ${ }^{7}$ Percebeu que estava rodeado pelo fogo e buscou uma saída para fugir das chamas. Encontrou outros sobreviventes que também buscavam refúgio do fogo e reparou que seus rostos tinham uma expressão de horror e medo. Imagina que também carregava a mesma expressão em sua face. Não conseguia entender por que todas as pessoas estavam caminhando nuas com as roupas em trapos penduradas pelo corpo, e só após chegar ao refúgio e poder olhar de perto esses feridos, notou que não se tratava de trapos pendurados, e sim pele queimada que se desprendia do corpo. Ficou chocado e horrorizado com o que estava tentando assimilar com os olhos.

O mesmo horror assolou Yoko Akiyama, ${ }^{8}$ que ao prestar ajuda aos refugiados que chegavam de regiões próximas ao epicentro, observava com horror suas roupas e pele se desprendendo de seus corpos como trapos. Recorda que "Havia um menininho cujo rosto e lábios estavam inchados, preto e azul. Ele gritava, 'Quem fez isso comigo!'” (Hiroshima Jogakuin Alumni Association, 2005, p.45, tradução nossa). Assim descreveu este cenário desolador: "Era como assistir ao próprio inferno" (Hiroshima Jogakuin Alumni Association, 2005 , p.45, tradução nossa). Um cenário repleto de fogo, pessoas mortas ou morrendo, gemidos e súplicas angustiadas por um pouco de água e a sensação de impotência daqueles que desejavam prestar socorro. Sequer água podia ser administrada aos moribundos como uma forma de conforto pois, naquela época, todos eram instruídos a não fornecê-la às vítimas de queimaduras para não agravar suas condições ou desencadear mortes precoces.

Ainda sobre o cenário infernal criado pela bomba, relata Mineko Komat$\mathrm{su}^{9}$ sobre sua volta para casa logo após a explosão:

Minha caminhada para casa foi miserável e infernal. Pessoas com os rostos roxos e duas vezes maiores que o normal por causa do inchaço; alguns com a pele do corpo toda descascada; indivíduos feridos com roupas esfarrapadas, todos cambaleavam em direção à montanha em busca de refúgio. Corpos estavam deitados por todos os lados, queimados, tão pretos que não era possível dizer se eram homens ou mulheres. Os rios estavam cheios de pessoas procurando a água que corria embaixo da pilha de corpos. (Hiroshima Jogakuin Alumni Association, 2005, p.58-59, tradução nossa)

Após a explosão uma grande nuvem em formato de cogumelo (mushroom cloud) se ergueu no ar e podia ser observada a quilômetros de distância do epicentro. Sua extensão era tão grande que muitos sobreviventes que perderam a consciência logo após a explosão, quando acordaram, se surpreenderam com a escuridão em que se encontravam. Katsuko Iida ${ }^{10}$ deparou com a monstruosa nuvem quando, após ouvir o terrível estrondo da bomba, subiu uma colina pró- 


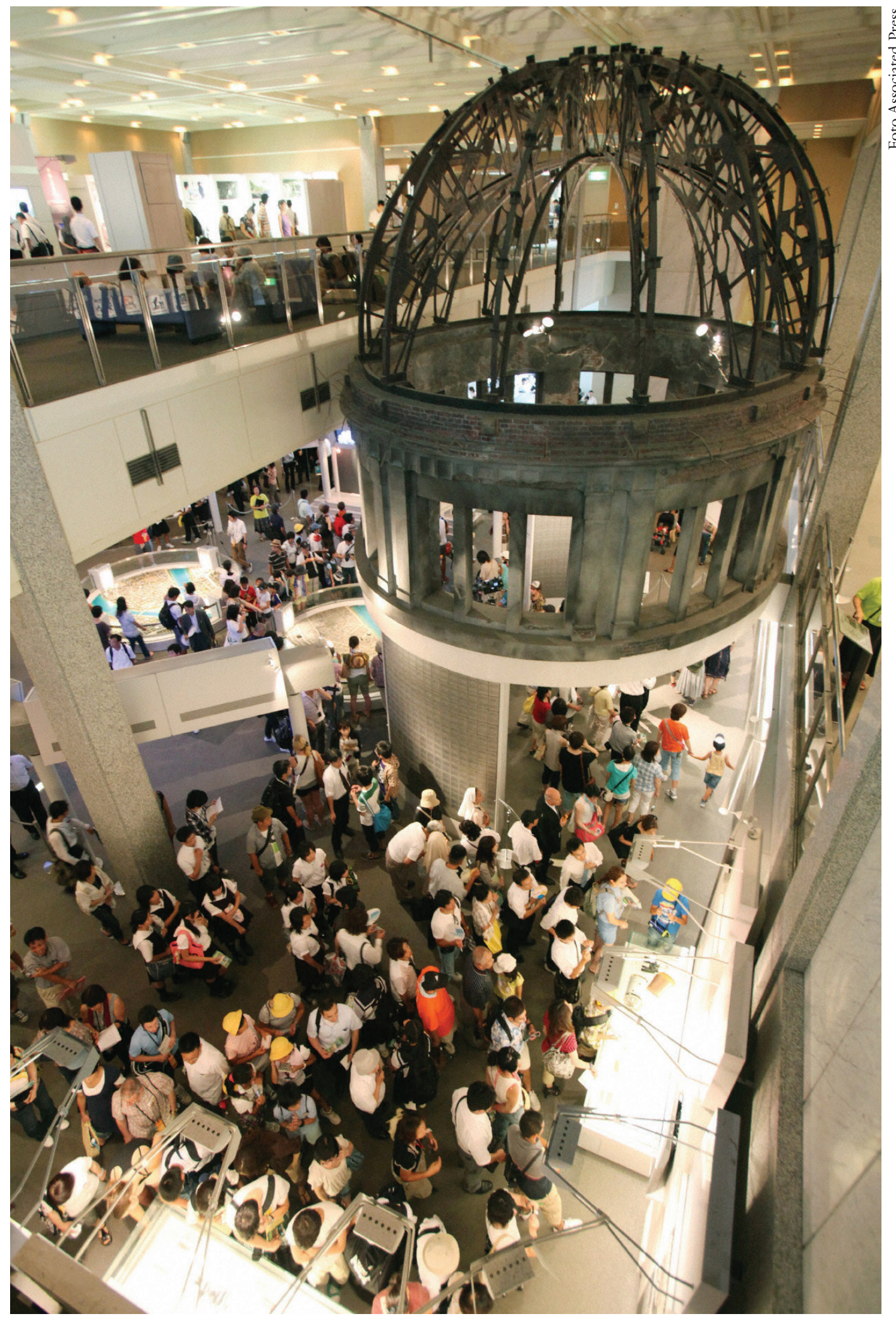

Musen Memorial da Paz de Hiroshima. 
xima ao local aonde acabara de chegar para o trabalho para tentar ver o que havia acontecido na cidade. Relata:

Eu olhei na direção de Hiroshima e vi uma nuvem em forma de cogumelo no céu. A fumaça estava se erguendo como se estivesse fervilhando do chão, espirrando para todos os lados e, em seguida, caindo. [...] A cidade toda estava queimando, criando um cenário infernal de pessoas fugindo, desabando, pulando nos rios, e morrendo. (Hiroshima Jogakuin Alumni Association, 2005, p.48, tradução nossa)

A grande nuvem ficou suspensa no ar entre aproximadamente 20 e 30 minutos, e foi se desfazendo à medida que os ventos sopraram na direção noroeste da cidade de Hiroshima, o que ocasionou a chamada "chuva negra" (black rain), assim denominada pela coloração negra das enormes gotas que, ao mesmo tempo, foram descritas como muito geladas. Hina Masuda ${ }^{11}$ afirma que a chuva negra era tão mortífera que abriu buracos enormes e tingiu de preto todas as roupas que pendurara no varal.

A cor da chuva foi determinada pela grande quantidade de poeira proveniente da explosão e dos incêndios que a grande nuvem em formato de cogumelo reteve. A chuva negra também continha grande quantidade de radiação. Testemunhos de sobreviventes apontam que aqueles que ficaram expostos à chuva negra morreram pouco tempo depois em decorrência da radiação excessiva. A chuva durou sete horas, das $9 \mathrm{~h} 00 \mathrm{~min}$ às $16 \mathrm{~h} 00 \mathrm{~min}$ (Kosakai, 1980).

Apesar de pouco atingidos, Tsuda e seus filhos se preparavam para se dirigir ainda mais para o interior quando a chuva negra começou a cair. Relata que resolveram esperar a chuva passar e, enquanto aguardavam, olhavam com apreensão para a grande nuvem em formato de cogumelo que se erguia sobre Hiroshima e para o reflexo avermelhado do fogo que engolia a cidade. Sem saber o que estava ocorrendo, Tsuda apenas rezava e se preocupava com sua família que estava na cidade. Sabia que não havia nada que ela pudesse fazer a não ser rezar.

Estima-se que aproximadamente 350 mil pessoas estavam em Hiroshima no momento da explosão da bomba atômica e a cidade de Hiroshima estima que, até dezembro de 1945, 140 mil pessoas morreram (Hiroshima Peace Memorial Museum, 1999). Segundo Thomas e Witts (2012), aproximadamente 80 mil civis morreram instantaneamente ou com feridas letais. Dos 200 médicos atuantes na cidade, 180 morreram. Dos 1.780 enfermeiros, 1.654 morreram e apenas três dos 55 hospitais de Hiroshima puderam atender os feridos pela bomba.

As estatísticas, entretanto, informam apenas o número de mortes, mas não explicam a forma como essas vítimas morreram. A maior parte dos testemunhos de sobreviventes que relatam a morte de outras pessoas informa que as vítimas feridas com graves queimaduras viveram horas de uma morte solitária e agonizante. Iida, em seu relato sobre o período compreendido entre 6 e 9 de agosto, descreve a morte cruel e solitária de uma mulher de aproximadamente dezoito 
anos que faleceu chamando por seu filho, um bebê que se perdeu na explosão. Essa jovem mulher morreu por causa de graves ferimentos, emudecida pela dor, preocupada e angustiada com o desaparecimento do seu filho, com os seios derramando o leite materno e, acima de tudo, completamente sozinha.

As vítimas civis eram principalmente crianças, adolescentes, mulheres e idosos. A maior parte dos homens em idade adulta havia sido recrutada para a guerra. Entretanto, por sediar quartéis generais e, dessa forma, uma cidade altamente militarizada (um dos motivos por ter sido escolhida como alvo do bombardeio atômico), havia no local algumas tropas japonesas com seus prisioneiros de guerra - entre eles alguns soldados norte-americanos capturados dias antes.

Após a explosão, houve dentro do Enola Gay um silêncio absoluto da tripulação, que relatou mais tarde ter sentido um gosto de chumbo em suas bocas proveniente da explosão e da onda de choque que os atingiu mas não os derrubou, graças à manobra de fuga executada por Tibbets.

Às 14h58min do dia 6 de agosto de 1945, o bombardeiro Enola Gay pousou na base de North Field após ter ficado 12 horas e 13 minutos no ar. Tibbets e sua tripulação foram recebidos com aplausos pelos seus colegas.

Enquanto a tripulação dos bombardeiros era aplaudida, o sobrinho de seis anos de Tsuda morria nos braços da mãe em decorrência dos ferimentos causados pela queda da casa onde estavam no momento da explosão e pela radiação a que foram expostos. Já Muraki descobria que sua família estava viva, refugiada em um templo chamado Yuishinji, e corria para encontrá-los. Chegando lá viu os pais cobertos por bandagens e sua irmã com a parte superior do corpo carbonizada pelas queimaduras, mas viva. Viu que as pessoas ao redor deles geminam de dor e choravam, pedindo ajuda e água. Algumas apenas emitiam barulhos de dor, mas estavam fracas e feridas demais para falar. Muraki afirma que jamais esquecerá daquela noite e daquele cenário infernal.

A aproximação da noite fez que as chamas que queimavam Hiroshima ficassem mais intensas e vivas. Muitas pessoas relatam ter passado horas olhando para as chamas ao anoitecer, ainda paralisadas e anestesiadas pelo trauma, sem saber o que sentir e o que pensar. Fusako Nobe ${ }^{12}$ afirma que passou a noite do dia 6 de agosto na margem de um dos rios de Hiroshima, cheio de pessoas queimadas, desfiguradas e inchadas. Assistiu a cidade ser engolida por chamas vermelhas ardentes que contornavam as inúmeras silhuetas de pessoas que estavam sendo queimadas vivas ou mortas. Mesmo longe dos incêndios, as pessoas que os contemplavam relatam o horror de sentirem a brisa quente carregada de um cheiro forte de carne humana sendo queimada.

Quando os incêndios diminuíram, muitas pessoas entraram na cidade em busca de familiares e amigos ou procurando saber o que aconteceu com suas casas. No caso de Hisako Nomura, ${ }^{13}$ ela e a irmã foram verificar o estado de sua casa após o incêndio. Nomura relata que ficou chocada com o que viu perto da ponte Aioi: 
A cidade estava infestada com o odor de corpos queimados, e os rios estavam cheios de mortos. Próximo à ponte Aioi, eu passei por um grupo de oito meninos mortos, todos em idade escolar, que foram queimados enquanto estavam deitados e segurando um a mão do outro, formando um círculo. Eu imagino que eles deveriam ter chamado os nomes um dos outros enquanto queimavam vivos. (Hiroshima Jogakuin Alumni Association, 2005, p.97, tradução nossa)

Da mesma forma, Nobuko Akiyama ${ }^{14}$ jamais se esquecerá de ter passado por uma casa totalmente destruída e de ter visto o corpo carbonizado de uma pessoa que estava presa embaixo dos escombros da construção em razão da explosão. Afirma que os braços dessa pessoa estavam esticados, como se estivesse agarrando a terra por conta da dor excruciante que sentia no momento da morte.

\section{Rendição do Japão}

Após o bombardeio à cidade de Hiroshima, o presidente americano Harry Truman fez um comunicado ao povo americano e ao mundo:

Dezesseis horas atrás um avião americano jogou uma bomba em Hiroshima, uma importante base militar japonesa. A bomba era mais poderosa que 20.000 toneladas de T.N.T. Sua explosão foi mais de duas mil vezes superior ao Grand Slam britânico, que é a maior bomba já usada na história da guerra.

Os japoneses começaram a guerra pelo ar em Pearl Harbor. Eles pagaram por isso amplamente. E o fim ainda não chegou. Com essa bomba nós agora adicionamos um novo e revolucionário aumento em termos de destruição, para suplementar o poder crescente de nossas forças armadas. Na sua forma presente, estas bombas já estão em produção e formas ainda mais ponderosas estão sendo desenvolvidas.

É uma bomba atômica. É o aproveitamento do poder básico do Universo. A força de onde o sol extrai seu poder foi solta contra aqueles que trouxeram a Guerra para o Extremo Oriente. (Kiernan, 2013 p.457-58, tradução nossa)

Após o pronunciamento do presidente dos Estados Unidos, o Vaticano se manifestou dizendo, segundo Thomas e Witts (2012 p.353, tradução nossa), que a nova bomba era uma "conclusão catastrófica para as surpresas apocalípticas da guerra". Comparou ainda a nova arma com a invenção do submarino por Leonardo Da Vinci, salientando que o artista, diferentemente dos cientistas que criaram a bomba, destruiu sua criação em nome da preservação da humanidade.

\section{Experiência e pesquisas: Hiroshima}

Após os bombardeios ao Japão e à chegada das equipes de pesquisa às cidades atingidas, os cientistas descobriram que a radiação penetra profundamente nos corpos dos indivíduos infectados, causando diversos problemas fisiológicos, cujos sintomas foram descritos aqui. Um dos resultados mais comuns é o comprometimento da medula óssea, o que ocasiona vários tipos de alterações 
no sangue das vítimas, muitas das quais desenvolveram doenças como a leucemia, por exemplo.

A exposição à radiação traz muitos sintomas semelhantes às vítimas. Porém, os órgãos mais atingidos não seguem um padrão linear de um indivíduo para outro. Muitos sobreviventes desenvolveram câncer, mas outros não chegaram a ser diagnosticados com a doença. Tudo dependeu, como no caso da sobrevivência à explosão, da forma com que as vítimas foram contaminadas, da distância em que se encontravam do hipocentro, da presença de uma barreira que impediu que toda a radiação emitida pela explosão atingisse diretamente as vítimas, do contato com a chuva negra ou da entrada na cidade após a explosão. Esses fatores casuais fizeram que Hiroshima e Nagasaki virassem, no período pós-guerra, grandes laboratórios a céu aberto, nos quais foi possível estudar amplamente os efeitos da radiação emitida pelas bombas atômicas em seres humanos.

A contaminação por radiação permaneceu nos solos da cidade por algum tempo após a explosão, depositada tanto pela própria explosão quanto pela nuvem em forma de cogumelo e pela chuva negra, todas extremamente radioativas. Isso fez que os indivíduos que não estavam na cidade no momento do bombardeio e, portanto, não haviam sofrido nenhum ferimento em decorrência da explosão fossem contaminados ao entrarem na cidade para prestar socorro às vítimas. Esses, em grande parte, morreram dias depois do bombardeio, sofrendo os mesmos sintomas daqueles diretamente expostos à radiação (Hiroshima Peace Memorial Museum, 1999).

Os sintomas mais frequentes observados desde as primeiras horas após a contaminação (efeitos agudos) foram: vômitos, vômitos com presença de sangue, estomatite, perda de apetite, diarreia, exaustão, insônia, febre alta, dores de cabeça, perda de cabelos, urina e fezes com sangue, distúrbios nos ciclos menstruais das mulheres, pintas roxas espalhadas pelo corpo (incluindo os dentes) e redução de diversas células sanguíneas (comprometimento da medula óssea) (Hiroshima Peace Memorial Museum, 1999).

Muitos indivíduos que aparentemente não apresentavam nenhum ferimento físico morreram em poucos dias em decorrência dos problemas causados pela contaminação radioativa. Já aqueles que apresentavam ferimentos físicos em decorrência da explosão tiveram seus sintomas agravados por infecções e, na maioria dos casos, morriam em poucas horas. Todos os casos eram agravados pela falta de alimentos, e, além da escassez de comida, muitos sobreviventes não conseguiam se alimentar em razão da ausência de apetite e/ou a presença de vômitos constantes.

Em dezembro de 1945, os sintomas agudos da radiação começaram a desaparecer. Porém, os efeitos da radiação iriam prejudicar para sempre a vida dos sobreviventes e de seus descendentes tendo em vista a sensação de cansaço constante, problemas com as células sanguíneas, esterilidade, abortos, diversos 
tipos de câncer (principalmente leucemia) e problemas na tireoide, entre outros. Houve muitos casos de mulheres que estavam grávidas no dia do bombardeio e que tiveram bebês com microcefalia ou, quando menos afetados, com algum grau de deficiência física e/ou mental. Pessoas que tiveram queimaduras no corpo sofreram pelo resto de suas vidas com dores e outros problemas resultantes da formação de queloides.

Esses sintomas estão presentes em muitos testemunhos de sobreviventes de Hiroshima. Kamatsuka afirma que:

Muitos que aparentavam saudáveis e sem ferimentos desenvolveram, subitamente, febre alta e diarreia. Seus corpos deterioraram, enquanto suas gengivas sangravam e seus cabelos caíam. Pessoas morreram de baixo das árvores e de prédios semidestruídos, enquanto chamavam, de seus abrigos, pelos nomes de seus familiares. (Hiroshima Jogakuin Alumni Association, 2005 , p.78, tradução nossa)

Reiko Kajitani ${ }^{15}$ relembra com pesar os cruéis efeitos que a bomba teve sobre os seres humanos, desde as queimaduras terríveis até os sintomas da radiação. Conta que ao chegar em casa, na cidade vizinha de Itsukaichi, ${ }^{16}$ viu espalhados pelos cômodos muitos refugiados feridos que fugiram de Hiroshima em busca de abrigo. Sobre uma dessas refugiadas, uma menina de quatro ou cinco anos que estava na companhia dos pais, Kajitani conta:

Seu corpo estava coberto de queimaduras. Eu não me lembro de seu nome verdadeiro, então a chamarei de Michiko.

Quando seu pai a carregava nas costas, Michiko gritava "Isto dói, isto dói". Minha mãe trouxe um cobertor para que ela pudesse deitar. Mesmo depois de deitada, Michiko continuava a chorar com uma voz fraca e protestava sobre sua dor. Minha mãe encontrou um velho kimono de verão e ferveu-o para o esterilizar e, então, rasgou-o em tiras para fazer bandagens. Nós tínhamos apenas um pequeno extrato de remédio para queimaduras que não era o suficiente para cobrir adequadamente as queimaduras de Michiko. Nós gentilmente enrolamos Michiko nas bandagens, mas como ela também queimara seu rosto, quando terminamos, ela parecia um pacote de bandagens. Todos os dias, Michiko gritava de dor até ficar exausta e adormecer [...].

Um dia aconteceu uma coisa que ficou gravada na minha memória até hoje. A voz de Michiko estava perdendo a força gradualmente. Meus pais estavam fora e eu estava lendo um livro ao lado dela quando, de repente, ela começou a falar enquanto dormia. Sua voz estava clara e forte. "Mamãe, as flores são tão lindas. Tem borboletas também. Olhe, ali! Você pode pegar uma para mim? Oh, lá está outra... rápido, rápido, lá!”

Assustada, eu abaixei o livro e olhei para o rosto de Michiko. Ela estava dormindo pacificamente e sonhando com um lindo campo de flores. Ela ficou neste ambiente onírico por um tempo, até que sua voz sumiu. Eu senti uma necessidade de pedir socorro, mas era tarde demais. Michiko morrera pacificamente. Finalmente, ela foi libertada da dor e do sofrimento. 
[...] Um dos refugiados, que estava hospedado na nossa sala de família, desenvolveu febre alta e ficou acamado. Havia manchas em sua pele e ele vomitava sangue. O médico da cidade disse: "Eu não tenho certeza de que doença é essa, mas creio que é contagiosa. Os jovens estão em perigo. Você deve manter esse paciente em quarentena. A escola primária está sendo usada como uma ala de isolamento. Leve-o para lá imediatamente".

[...] Assim que o paciente foi levado, nós esterilizamos o tatami da sala de família. [...] Em retrospectiva, eu me dei conta que sua doença não era epidêmica, mas o efeito da exposição à radiação. Mas naquele tempo, nós éramos ignorantes sobre o tipo de bomba que caiu e ninguém nunca havia escutado sobre a bomba atômica ou a radiação. (Hiroshima Jogakuin Alumni Association, 2005, p.36, grifo nosso, tradução nossa)

Kajitani retrata em seu testemunho o drama vivido pelos milhares de sobreviventes do bombardeio. O cenário caótico em que a explosão deixou a cidade, acompanhado da morte do maior número de médicos e enfermeiros que atuavam em Hiroshima, assim como a ausência de medicamentos e estrutura adequada para tratar os feridos, fez que a maior parte das pessoas, como Michiko, oscilasse entre a inconsciência causada pela debilidade de seus corpos feridos e pelo trauma, e a consciência repleta de dor e sofrimento. Oscilavam até o momento em que seus corpos não aguentavam mais. Quando conseguiam encontrar um médico em condições físicas e psíquicas para atender os feridos, percebiam esses mesmos sentiam-se impotentes ante os sintomas da radiação que lhes eram completamente desconhecidos.

A morte imposta às vítimas do bombardeio atômico foi desumana na medida em que não somente matou milhares de pessoas no exato momento da explosão, mas também deixou outras milhares agonizando durante horas e mesmo dias até o momento de suas mortes. Para os sobreviventes, ficou ainda a indignação pelo fato de que nenhum socorro, fosse dos norte-americanos, fosse dos próprios japoneses, chegou à cidade para aliviar o sofrimento dos que estavam gravemente feridos. Quem prestou socorro no dia da explosão foram os civis, em sua grande parte os sobreviventes que se encontravam menos machucados ou menos afetados pelos sintomas da radiação e, assim, puderam dar aos moribundos um certo conforto antes de suas mortes.

Após a rendição do Japão, as equipes de pesquisa do general Farrell entraram em Hiroshima e a ocuparam juntamente com o exército. Trouxeram consigo alguns medicamentos e equipamentos e foram ao encontro dos sobreviventes que se encontravam espalhados pelos vários lugares que serviram como postos de primeiros socorros. Entretanto, como relatam vários hibakushas indignados, os norte-americanos estavam tão atentos aos sintomas e observando cuidadosamente os ferimentos e o estado das vítimas que pouco ajudaram no alívio das dores e sintomas da radiação. Aparentemente, desejavam observar, estudar e registrar como a contaminação radioativa se manifestava no homem até o momento de seu óbito. 
Ao longo dos meses, a rotina de pesquisas dos cientistas e médicos do Projeto continuou. Documentaram vários tipos de ferimentos e queimaduras, assim como os sintomas e a forma pela qual a radiação atuava nos diferentes organismos. Houve médicos que, tomados por alguma compaixão, de fato se comprometeram com a tarefa de tratar seus pacientes. No entanto, a impressão que a população teve foi que os norte-americanos instalaram um grande laboratório na cidade e eles, as vítimas, não eram pacientes, mas meras cobaias de um experimento científico. Mesmo depois de muitos anos, os médicos continuaram a acompanhar os sobreviventes e seus familiares que, ao longo da vida, desenvolviam cânceres e variados distúrbios em diferentes órgãos. Pesquisas sobre o progresso dessas doenças ainda estão em andamento, e os hibakushas passam por avaliações anuais sobre seu estado de saúde.

$\mathrm{Na}$ ditadura de Hitler, dentro dos campos de concentração, vítimas eram selecionadas para servir como cobaias humanas em experiências em prol do conhecimento e do desenvolvimento científicos. Os Estados Unidos fizeram o mesmo, apenas com um método diferente de impor a crueldade às suas vítimas.

Nesse contexto, Hobsbawm (2013, p.357) afirma:

Como hoje sabemos, graças às revelações da administração Clinton, os EUA, desde o imediato pós-guerra até plenos anos 1970, envolveram-se em experimentos com radiação em seres humanos, selecionados entre aqueles avaliados como socialmente inferiores. Como as experiências nazistas, eram conduzidos ou pelo menos monitorados por médicos, profissão cujo membros, devo dizer com pesar, frequentemente se permitiram envolver na prática da tortura em todos os países. Pelo menos um dos médicos norte-americanos que acharam repugnantes tais experimentos protestou a seus superiores que parecia haver neles "um cheiro de Buchenwald". É seguro supor que não fosse o único a perceber a similaridade.

Para os sobreviventes, saber que todo o horror que lhes foi imposto havia sido parte de uma experiência científico-política, do teste de uma nova arma em seres humanos, foi algo incompreensível e traumático. Como se não bastasse, ainda tiveram que lidar com a obrigação de serem acompanhados pelos médicos e cientistas do Projeto que monitorariam sua saúde e as doenças causadas pela radiação nuclear. Ou seja, aqueles que indiretamente lhes causaram os males os estudariam até a hora de suas mortes.

Segundo algumas vítimas, serem acompanhadas pelos pesquisadores era terrível e humilhante porque os profissionais as tratavam como objetos, sujeitos de experimentos. Uma das testemunhas que deixou suas memórias disponíveis no acervo do Memorial da Paz de Hiroshima conta que se envergonhava muito de seu corpo coberto por queloides decorrentes das queimaduras causadas pela explosão. Relata que sempre que ia para os exames de rotina sentia-se tomada por muita angústia e tristeza. Entrava em uma sala cheia de homens (médicos e outros pesquisadores) que a mandavam tirar toda a roupa. Quando despida, 


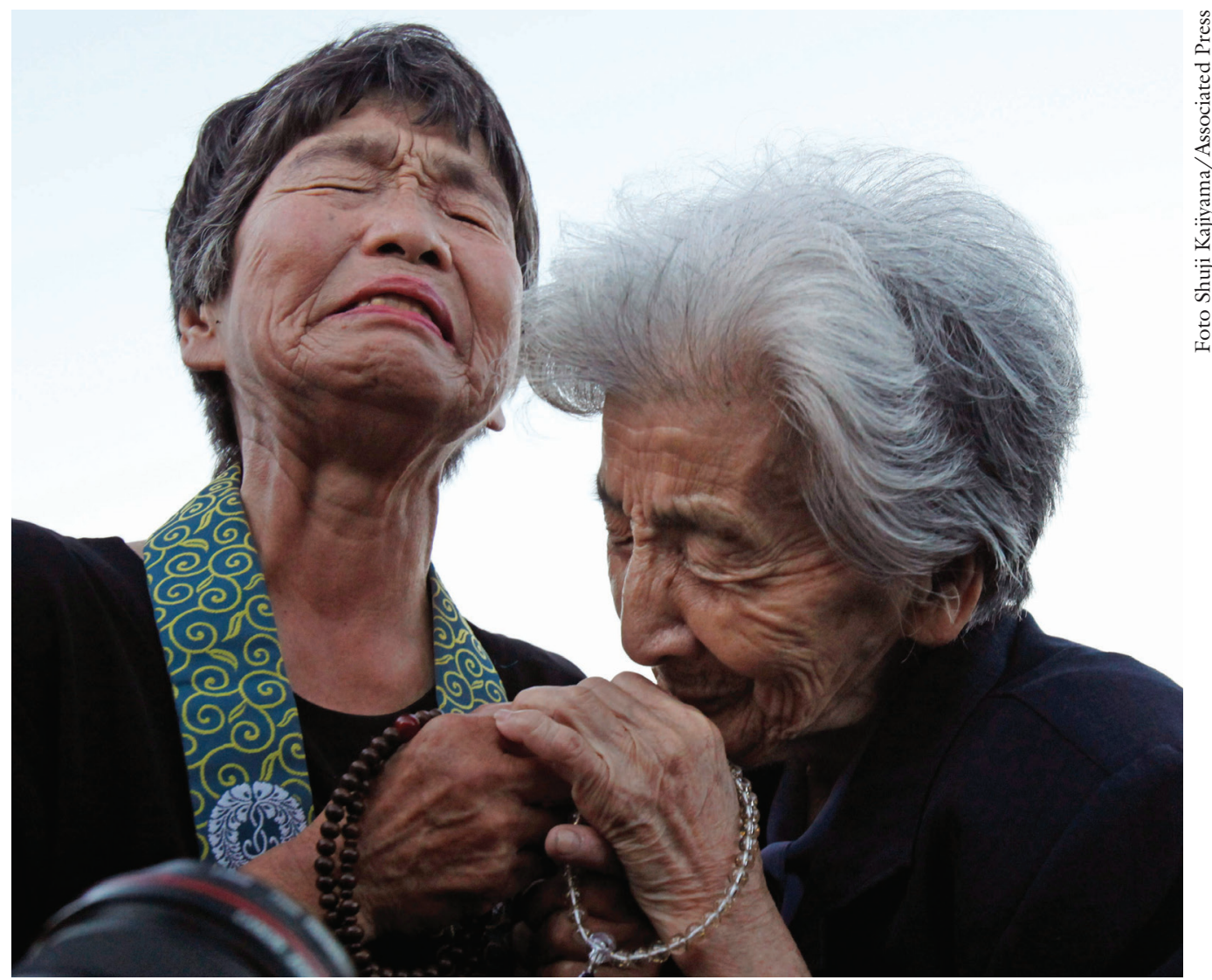

Familiares de vitimas da bomba rezam juntas.

obrigavam-na a ficar de frente para ser fotografada e observada. Após algum tempo, mandavam-na virar de costas e o mesmo procedimento se repetia.

A sobrevivente afirma que sentia que os olhares sobre ela não percebiam que ela era uma mulher, um ser humano, provida de vergonha, pudor e sentimentos. Apenas a tratavam como um objeto experimental. Lembra-se com muito sofrimento que ao ficar parada, nua, exposta aos vários olhos, ouvia os pesquisadores conversarem entre si, rirem de coisas mundanas, como se ela não estivesse lá e aquela sessão de horror fosse algo cotidiano e sem importância.

Outros sobreviventes mostram sua indignação ante a indisposição desses médicos em tratarem as dores físicas das queloides e alguns sintomas da radiação que não os abandonavam. Apenas faziam perguntas, tiravam fotos dos ferimentos externos, anotavam em prontuários os sintomas e dispensavam as vítimas.

Porém, alguns testemunhos também se referem a ajuda de muitos norte-americanos que não concordaram com os bombardeios atômicos e julgavam como lamentável a atitude autoritária de seu governo, que agiu sem a aprovação de seu eleitorado ou do Congresso. Com um grande sentimento de culpa, esses cidadãos buscaram fazer o possível para ajudar as vítimas de Hiroshima e Naga- 
saki. Alguns cirurgiões plásticos, por exemplo, chegaram a operar sobreviventes do sexo feminino na tentativa de diminuir a quantidade de cicatrizes que as marcaram para sempre.

No dia em que Hiroshima foi bombardeada, havia na cidade padres e missionários norte-americanos que também sofreram com a arma lançada por seu país. Esses se dedicaram incansavelmente ao resgate e ao salvamento de sobreviventes tanto no dia do bombardeio como nos dias próximos à explosão. Em seu livro, Hersey (1989) escreve sobre alguns grupos nos Estados Unidos que buscaram auxiliar os sobreviventes por meio do levantamento de verbas e denúncias públicas sobre o que ocorreu em Hiroshima no dia da 6 de agosto de 1945. O próprio autor americano escreveu seu livro como uma forma de denunciar e contar a história do bombardeio do ponto de vista das vítimas, marcando a grande importância dos testemunhos no período pós-guerra.

Através do ato de testemunhar, muitos sobreviventes conseguiram se desvincular do papel de cobaias que lhes foi imposto, de vítimas ou fatalidades de guerra - papéis de certo modo passivos - para ocupar um espaço fundamental na construção da história humana, atestando que a guerra tem um determinado caráter para o governo e para a política, mas possui uma conotação totalmente distinta para a população civil, que sofre as consequências dessa mesma guerra. Esses hibakushas passaram a acreditar que as vítimas das guerras, os civis, possuem a obrigação moral e o compromisso com a humanidade de levantar suas vozes para se consolidar como indivíduos integrantes de uma sociedade que os observa não como seres descartáveis, pois são parte integrante da nação e é por eles que seus governos devem zelar.

\section{Notas}

1 Todos os horários mencionados serão referentes ao Japão.

2 Sobrevivente da bomba de Hiroshima. Tinha 23 anos em 1945 (Hiroshima Jogakuin Alumni Association, 2005, p.24-27).

3 Motivo pelo qual, no teste Trinity, a bomba foi colocada a 30 metros do solo.

4 Epicentro: refere-se ao ponto no ar em que a bomba atômica explodiu, sendo seu referencial no solo denominado hipocentro.

5 Sobrevivente da bomba de Hiroshima (Hiroshima Jogakuin Alumni Association, 2005, p.28-9).

6 Sobrevivente da bomba de Hiroshima. Tinha 17 anos em 1945 (Hiroshima Jogakuin Alumni Association, 2005, p.108-12).

7 Streetcar é uma espécie de bonde utilizado pela população para se locomover nas áreas centrais da cidade de Hiroshima.

8 Sobrevivente da bomba de Hiroshima. Tinha 18 anos em 1945 (Hiroshima Jogakuin Alumni Association, 2005, p.44-7).

9 Sobrevivente da bomba de Hiroshima. Tinha 18 anos em 1945 (Hiroshima Jogakuin Alumni Association, 2005, p.58-9). 
10 Sobrevivente da bomba de Hiroshima. Tinha 18 anos em 1945 (Hiroshima Jogakuin Alumni Association, 2005, p.48-52).

11 Sobrevivente da bomba de Hiroshima. Tinha 24 anos em 1945 (Hiroshima Jogakuin Alumni Association, 2005, p.19-23).

12 Sobrevivente da bomba de Hiroshima. Tinha 16 anos em 1945 (Hiroshima Jogakuin Alumni Association, 2005, p.92-94).

13 Sobrevivente da bomba de Hiroshima. Tinha 16 anos em 1945 (Hiroshima Jogakuin Alumni Association, 2005, p.95-9).

14 Sobrevivente da bomba de Hiroshima. Tinha 17 anos em 1945 (Hiroshima Jogakuin Alumni Association, 2005, p.115-20).

15 Sobrevivente da bomba de Hiroshima. Tinha 19 anos em 1945 (Hiroshima Jogakuin Alumni Association, 2005, p.30-43).

16 As cidades vizinhas mencionadas nos testemunhos dos sobreviventes de Hiroshima eram distantes do epicentro em apenas alguns quilômetros. Por esse motivo, muitas dessas pequenas cidades receberam reflexos do bombardeio, como construções desabando ou a chuva negra.

\section{Referências}

BENJAMIN, W. Teorias do fascismo alemão: sobre a coletânea Guerra e Guerreiros, Editada por Ernst Jünger. In: Magia e técnica, arte e politica: ensaios sobre literatura e história da cultura. São Paulo: Brasiliense, 2012 (Obras Escolhidas, v.1, p.63-76). HERSEY, J. Hiroshima. New York: Vintage Books, 1989. 152p.

HIROSHIMA JOGAKUIM ALUMINI ASSOCIATION. For Those Who Pray For Peace. $1^{\text {a }}$ Edição. Hiroshima: Matsui Printing, 2005. 383p.

HIROSHIMA PEACE MEMORIAL MUSEUM. The Spirit of Hiroshima. Hiroshima: The City of Hiroshima, 1999. 127p.

HOBSBAWM, E. Sobre História. São Paulo: Companhia das Letras, 2013. 435p.

KIERNAN, D. The Girls of Atomic City: The Untold Story of the Women Who Helped Win World War II. Touchstone, 2013. 744p.

KOSAKAI, Y. Hiroshima Peace Reader. Hiroshima Peace Culture Foundation, 1980.

THOMAS, G.; WITTS, M. M. Enola Gay. Premier Digital Publishing, 2012. 431p.

RESUMO - Ao longo das duas Guerras Mundiais, observou-se o rompimento da humanidade com as normas de conduta inauguradas pelo Iluminismo, legitimando a violência como algo intrínseco à sociedade moderna. Essa mudança de valores foi acompanhada pelo crescente investimento científico e tecnológico, que atingiu um elevado desenvolvimento durante o século XX e trouxe, como um de seus resultados, os maiores genocídios realizados pelos Estados autoritários em nome de seus interesses políticos e econômicos. A barbárie nos leva a considerar um elemento para a reflexão: as testemunhas. Essas corporificam a necessidade de um resgate da humanização, da retomada dos valores morais perdidos com a banalização da violência. Assim, o testemunho confronta a história e demonstra que o desenvolvimento tecnológico não é sinônimo de desenvolvimento humano. Pelo contrário, permite questionar a verdadeira intenção das nações que, em busca de hegemonia, destroem maciçamente populações inteiras. 
Nesse contexto, emergem as seguintes questões: o que é o testemunho e qual a sua importância para a sociedade moderna? O que levou, historicamente, ao surgimento das testemunhas? Qual o contexto histórico que proporcionou o desenvolvimento da bomba atômica? Por que houve a necessidade, por parte das nações em guerra, de exterminarem milhares de pessoas, principalmente civis? Qual a consequência do rompimento das normas de civilidade pelas duas Guerras Mundiais? Para responder a essas perguntas, investigou-se o Museu Memorial da Paz de Hiroshima no que diz respeito à sua exposição permanente, seus objetivos no que se refere à luta contra o esquecimento da catástrofe atômica e à coleta de testemunhos. Após esse primeiro momento da pesquisa, procedeu-se ao estudo do contexto histórico que culminou nas atrocidades cometidas ao longo das duas Grandes Guerras, os resultados dos extermínios em massa para a sociedade moderna e, finalmente, o estudo sobre o trauma e o testemunho em relação aos sobreviventes do bombardeio atômico de Hiroshima.

PALAVRAS-CHAVE: Hiroshima, Segunda Guerra Mundial, Bomba atômica, Trauma, Testemunho.

ABSTRACT - Throughout the two World Wars, a disruption between humankind and the standards of conduct inaugurated by the Enlightenment was observed, legitimizing violence as something intrinsic to modern society. This change in values was followed by the increasing scientific and technological investment, which reached a high development during the twentieth century and brought, as one of its results, the greatest genocides carried out by the authoritarian States on behalf of their political and economic interests. The barbarism leads us to consider an element for reflection: the witnesses. They embody the need for redemption of humanization and the resumption of the moral values, both lost in the trivialization of violence. Thus, the testimony confronts history and shows that technological development is not a synonymous for human development. On the contrary, they allow us to question the true intent of the nations that, in their quest for domination, massively destroy entire populations. In this context, the following questions arise: what is the testimony and what is its importance to modern society? Historically, what had led to the appearance of witnesses? What is the historical context that provided the development of the atomic bomb? Why was there the need, by the nations at war, to exterminate thousands of people, mainly civilians? What is the consequence of breaking the rules of civility by the two World Wars? To answer these questions, the Hiroshima Peace Memorial Museum was investigated regarding its permanent exhibition, its goals regarding the struggle against forgetting the atomic disaster and the gathering of testimonies. After this first stage of the research, it was proceeded the study of the historical context that culminated in the atrocities committed during the two Great Wars, the results for modern society of the mass exterminations and finally, the study of trauma and testimony regarding the survivors of the Hiroshima atomic bombing.

KErWORDS: Hiroshima, Second World War, Atomic bomb, Trauma, Testimony.

Cristiane Izumi Nakagawa é bacharel e mestre em Psicologia pelo Instituto de Psicologia da Universidade de São Paulo. @ - cristiane.izumi@gmail.com

Recebido em 5.5.2015 e aceito em 20.5.2015.

I Instituto de Psicologia, Universidade de São Paulo. São Paulo/SP, Brasil. 
